\title{
About the Law of Friction
}

\section{Leonid Sosnovskiy}

Scientific \& Production Group TRIBOFATIGUE

Sergei Sherbakov ( $\square$ sherbakovss@mail.ru )

BSU: Belorusskij gosudarstvennyj universitet https://orcid.org/0000-0001-6404-6129

Viktor Komissarov

Belarusian State University of Transport

\section{Research Article}

Keywords: friction law, tribology, Tribo-Fatigue, friction pair, tribo-fatigue system, friction force and coefficient

Posted Date: August 31st, 2021

DOI: https://doi.org/10.21203/rs.3.rs-829511/v1

License: (c) (1) This work is licensed under a Creative Commons Attribution 4.0 International License.

Read Full License 


\title{
About the law of friction
}

\author{
Leonid A. Sosnovskiy ${ }^{1}$, Sergei S. Sherbakov ${ }^{2 *}$, Viktor V. Komissarov ${ }^{3}$ \\ ${ }^{1}$ Scientific and Production Group TRIBOFATIGUE Ltd., 246050 Gomel, Belarus; tribo-fatigue@mail.ru \\ ${ }^{2}$ State Committee on Science and Technology of the Republic of Belarus, 220072 Minsk, Belarus \\ 3 Byelorussian State University of Transport, 246653 Gomel, Belarus; vickom@ @ut.by \\ * Correspondence: sherbakovss@mail.ru
}

\begin{abstract}
The empirical law of dry friction, first formulated by Leonardo da Vinci 500 years ago, entered the history of technology as one of the most applicable laws in engineering calculations. Two hundred years later (after da Vinci) Amonton M., Coulomb C. A. and Euler L. made a decisive contribution to the substantiation and understanding of the law of dry friction, and it became classical: the friction force during sliding is proportional to the contact load. Studies have shown that the classical friction law for the tribo-fatigue system is inaccurate and, therefore, inapplicable. It was established experimentally that the error in estimating the coefficient of friction in a tribo-fatigue system (for example, a wheel / rail type, etc.) reaches $60 . .70 \%$ or more, if we use the classical law of friction for its analysis. Therefore, the problem arises of adjusting the classical law of friction. A set of theoretical and experimental studies was carried out, the results of which allowed to formulate a generalized law of friction: the friction force is proportional to both contact and non-contact volume loads, if the latter excites a cyclic stress (strain) field in the friction zone. This law describes all the experimental results (more than 100 values of the friction coefficient) with an error of no more than $\pm 6 \%$. The widespread use of the generalized law of friction in the technique proposed by us is considered a very urgent task.
\end{abstract}

Keywords: friction law, tribology, Tribo-Fatigue, friction pair, tribo-fatigue system, friction force and coefficient.

Generalized law of friction is a physical law according to which the friction force is proportional to both contact and non-contact (volumetric) load, if the latter excites a field of cyclic stresses (deformations) in the friction zone $[1,2]$. The law of friction is called generalized, since it adequately describes external friction in mechanical systems under the action of almost any non-contact loads (tension-compression, torsion, bending, bending with torsion, etc.). A special case of the generalized law of friction is the classical law of dry friction [3]: the friction force during sliding is proportional to the contact load (identically equal to the normal reaction).

\section{History}

The empirical law of dry friction [3-7], first formulated by Leonardo da Vinci more than 500 years ago, went down in the history of technology as one of the most used laws in engineering calculations [4]. Moreover, our worldview is inconceivable without an understanding of the universal processes of motion with friction (as well as motion without friction).

In Figure 1 [8], the oval marks the names of scientists whose contribution to the formulation and study of the dry friction law is considered decisive $[3,7,9-10]$. Their photographs are posted here. In Figure 1 on the right, the list of research objects is extremely simplified.

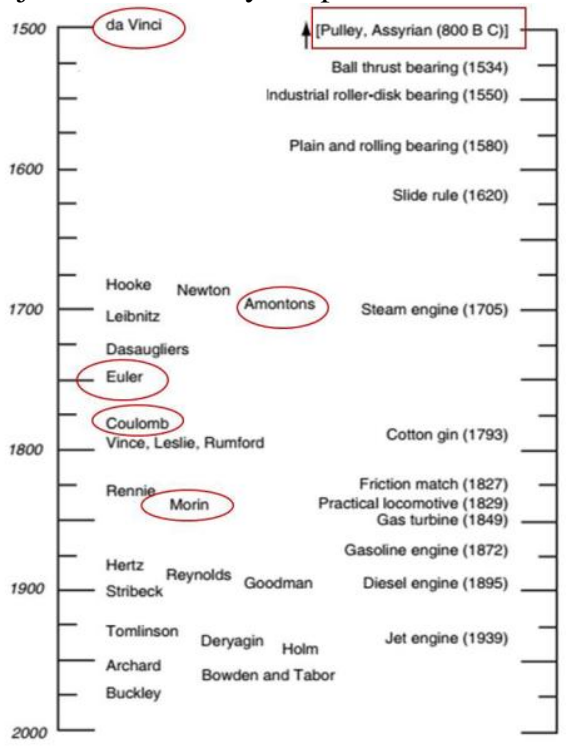

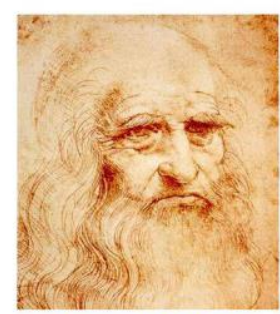

Leonardo da Vinci (1452-1519)

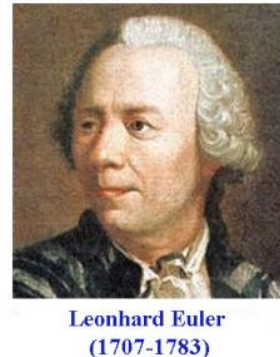

(1707-1783)

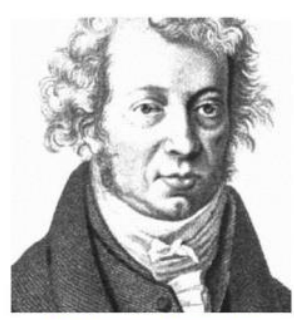

Guillaume Amontons $(1663-1705)$

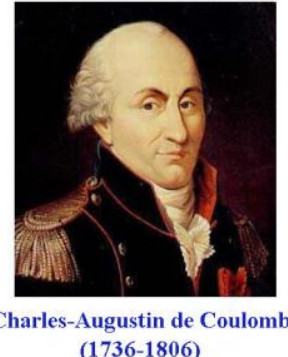

Figure 1 - To the history of the law of dry friction 
Leonardo da Vinci [4-5] is the first of the researchers of friction forces (1493-1494). His description of friction processes was as follows. The friction force depends on the material of the contacting surfaces, as well as on the degree of their processing. It does not depend on the contact area and is directly proportional to the weight of the load. The frictional force can be reduced by introducing lubricants between the rubbing surfaces. Every body exerts a resistance equal to one quarter of its weight during friction. As you can see, an almost exhaustive description of the dry friction law is given here and a numerical value $(0.25)$ of the friction coefficient is established. The independence of the friction force from the contact area is confirmed by the observation that it turns out to be the same for a rope coil and for a rope stretched into a line. However, in the literature, the law of friction is not called Leonardo da Vinci's law. This, apparently, is due to the fact that his works were presented in a manuscript that remained unknown for a long time.

About 250 years later (after da Vinci), Leonhard Euler made a significant contribution to the study and understanding of the dry friction law [11]. According to Euler, experience shows that the friction force is always equal to some part of the pressure with which the body is pressed against the plane on which it slides. Friction does not depend on either the size of the contact area or the magnitude of the speed. The effect of friction in a variety of machines can be calculated as a constant force opposite to the direction of travel; it lies in the plane of contact of bodies sliding over each other. Euler was the first to notice that starting friction was superior to sliding friction. This is a discontinuity of the first kind in the dependence of force on velocity at zero velocity. It requires concretization at the point of rupture from the conditions of equilibrium of the body. Taking into account the foregoing, in [4] it is proposed to call the dry friction law the Coulomb - Euler law.

Charles-Augustin de Coulomb [12] conducted fundamental experiments to establish the law of dry friction in 1779-1781. The experiments were carried out for different materials, different contact loads and different sizes of the test body. In each experiment, the ratio of the contact load to the friction force was recorded (the inverse coefficient of the coefficient, which is now called the dry friction coefficient). To determine that the friction force does not depend on speed, he applied a force to the loaded slide lying on the table along the axis of their symmetry. As a result, the sled started to move. With the help of a ruler and a stopwatch, it was established that the movement was uniformly accelerated. This meant: the friction force does not depend on the speed, otherwise the motion could not be uniformly accelerated. Knowing the acceleration, it is easy to calculate both the applied horizontal force and the friction force.

Despite the fact that Coulomb does not have such a clear and compact formulation of the dry friction law as Euler's, one cannot underestimate his contribution to the development of this law. Euler and Coulomb are the fullfledged founders of the science of friction. At the same time, Euler gave the direction of the mathematical approach to the problem, and Coulomb - the physical one.

The dry friction law is often called the Amontons - Coulomb law in the literature. The French mechanic Guillaume Amontons [13-14], almost 200 years after Leonardo da Vinci, repeats his results. The proof that friction does not depend on the contact area of the rubbing surfaces, he carries out more carefully than Leonardo da Vinci, and the value of the friction coefficient (1/3) indicated by him is significantly less than that of the latter.

In France, some experts call the law of friction the law of Morin [15], paying tribute to the complex of his well-known experiments, carried out about 50 years after the work of Euler and Coulomb. However, as noted in the literature, Morin has no fundamental achievements in understanding the dry friction law. In connection with the above, it seems that the law of friction should be named after Da Vinci - Amontons - Coulomb - Euler, which would be historically true (see Figure 1).

Thus, for about 300 years, experts have associated the characteristics of friction only and exclusively with the action of a contact load during motion [8-10, 16-46]. This is natural, since the friction units are characterized by relative motion (rotational, translational, reciprocating, etc.) and contact interaction of the body and the counterbody.

In the last quarter of the 20th century, the realization came that in tribo-fatigue systems (TFS), for example, of the wheel / rail type, friction processes are implemented against the background of repeatedly variable volumetric deformation of at least one of the interacting elements (rail in the wheel / rail system) [47-49]. This led to the general conclusion that non-contact cyclic loads (under tension, compression, bending, torsion, etc.) can, depending on the operating conditions or tests, significantly increase or decrease the force and friction coefficient in the system [50-52]. It was experimentally established that the change in the characteristics of friction in a TFS in comparison with a similar friction pair (FP) can be 10-20\% or more [53-56]. This means that the non-contact load can be considered as an additional parameter for effective control of friction processes. In this regard, a set of studies was set and carried out to study the effect of volumetric deformation on the change in the characteristics of friction and wear (the opposite effect in Tribo-Fatigue [50-52]). The results of such studies required the correction of the classical law of dry friction so that it could adequately describe the processes of friction in the TFS.

Three approaches to the estimation of the friction parameters in the TFS have been implemented:

- phenomenological - based on the study of the stress state in the area of contact, conditioned as a contact and non-contact (volumetric) loads; 
- deformation (theoretical) - based on the methods of deformable solid mechanics, mechanics of contact interaction and the theory of elasticity;

- experimental - based on the original methodology for TFS testing.

All three approaches lead to a unified formulation of the generalized law of sliding and rolling friction: the friction force is proportional to both contact and non-contact loads if they cause cyclic stresses (deformations) in the contact zone. Thus, the classical empirical law of dry friction is its special case.

\section{Phenomenological approach}

The effect of the stress state in the TFS on the possible change in the friction force in it in comparison with the analogous one in the friction pair (FP) is illustrated in Figure 2. If the bending moment $M(t)=0$, then, in the particular case of the FP (see Figure 2,b), according to the classical law, it is possible to indicate two interrelated characteristics of unidirectional sliding friction: the friction force

$$
F_{S}=f_{s} F_{N}=\tau_{w} A_{a}
$$

and the friction coefficient

$$
f_{s}=\frac{F_{S}}{F_{N}}=\frac{\tau_{w}}{p_{a}} .
$$

If there is no sliding (the shaft does not rotate: $\omega=0, F_{S}=0$ ), then, in the special case of the FP (see Figure 2, c), two similar characteristics describe the slipping during cyclic deformation of the shaft (it is marked by the subscript $\mathrm{c}$ in the formulas): cyclic friction force

and the cyclic friction coefficient

$$
\pm F_{c}=f_{c} F_{N}=\sigma A_{a}=M \frac{A_{a}}{W},
$$

$$
\pm f_{c}=\frac{F_{c}}{F_{N}}=\frac{\sigma A_{a}}{F_{N}}=\frac{M}{F_{N}} \frac{A_{a}}{W},
$$

where $W$ is the moment of resistance of the shaft to bending.

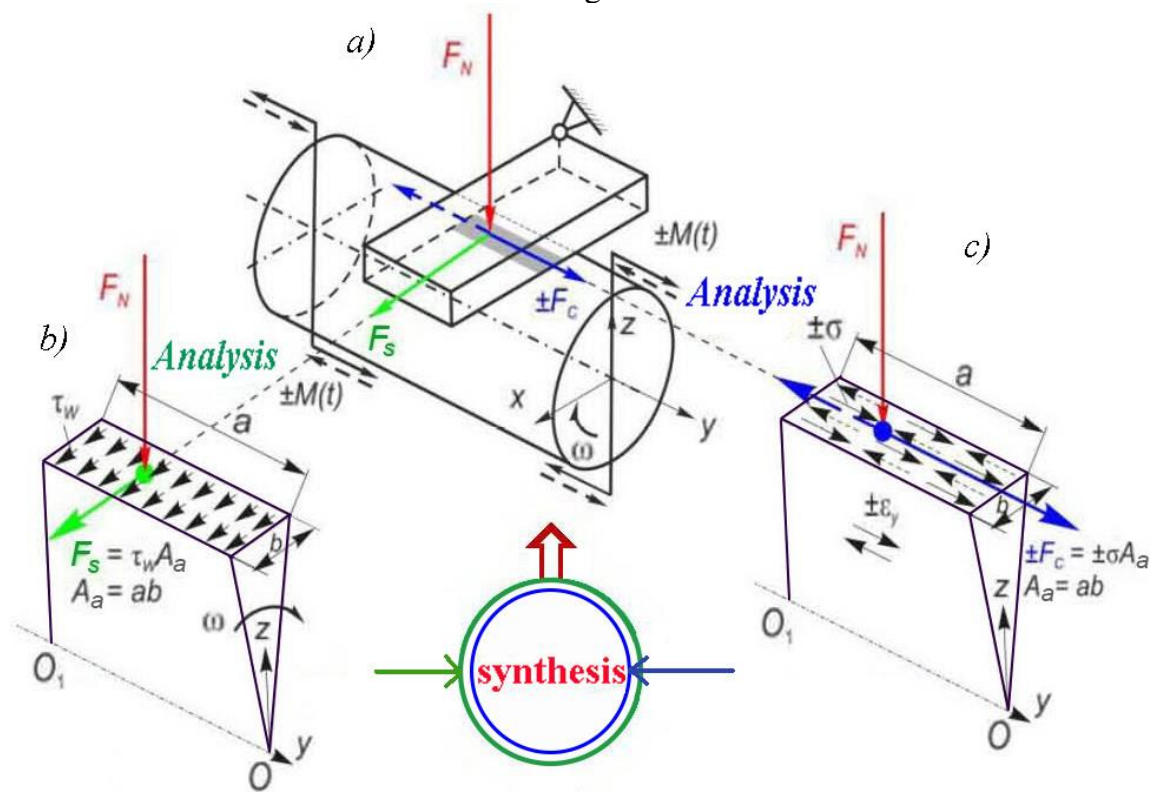

Figure 2 - Scheme of TFS plate / shaft $(a)$, stress distribution on the contact area in particular cases of friction pairs $(b, c)$ during sliding $(b)$ and during slipping $(c)$

Cyclic stresses can change sign $( \pm \sigma)$, that is, either compressive stresses $(-\sigma)$ or tensile stresses $(+\sigma)$ appear in the friction zone, due to the corresponding alternating load $( \pm M)$.

In the TFS, two components $\left(F_{s}\right.$ and $\left.F_{c}\right)$ of the friction force act simultaneously on the same contact area $A_{a}$, which leads to the excitation of a flat system of friction $\left(\tau_{w}\right)$ and cyclic $\left(\sigma_{a}\right)$ stress fields on it (see Figure $2, a, b, c$ ). And then the similar characteristics of friction will be: the generalized law of friction for the TFS in terms of stresses

in terms of forces

$$
\tau_{w / \sigma}=\tau_{w} \pm \mu_{\tau} \sigma_{a}=\tau_{w}\left(1 \pm \mu_{\tau} \frac{\sigma_{a}}{\tau_{w}}\right)=\tau_{w}\left(1 \pm \mu_{\tau} f_{F}\right),
$$

$$
F_{s / \sigma}=F_{s} \pm \mu_{\tau} F_{c}=f_{s} F_{N} \pm \mu_{\sigma} M, \mu_{\sigma}=\mu_{\tau} \frac{A_{a}}{W}
$$


as well as the generalized friction coefficient

$$
f_{s / \sigma}=\tau_{W} \pm \mu_{\tau} \sigma_{a}=f_{s}\left(1 \pm \mu_{p} \frac{\sigma_{a}}{p_{a}}\right)=f_{s}\left(1 \pm \mu_{p} f_{F}\right), f_{F}=\frac{\sigma_{a}}{p_{a}} .
$$

This formula is used to predict the coefficient of friction in the TFS, if the friction coefficient for the corresponding FP is known. The $f_{s}$ values for typical FPs are known and are given in tables [57]. The graphical representation of the predictive function has two branches: for friction either in the compression zone $\left(\sigma_{a}<0\right)$ or in the tension zone $\left(\sigma_{a}>0\right)$ of the bent shaft.

Thus, the generalized law of friction for the TFS states: in the general case, the friction force in the TFS is proportional to both contact and non-contact (volumetric) loads, if the latter excites cyclic stresses in the friction zone. When $\sigma_{a}=0$ and, therefore, $\mu_{\tau}=0$, the generalized law of friction is reduced to a particular case of the law of dry friction.

The peculiarity of the generalized law is that an additional proportionality coefficient $\mu_{\tau}$ is introduced here, which ensures the transformation of the component $\pm \sigma_{a}$ (the cyclic component of the specific friction force in the TFS) to the orthogonal component $\tau_{w}$ (the static component of the friction force in the TFS) so that their the algebraic sum $\left(\tau_{w} \pm \mu_{\tau} \sigma_{a}\right)$ was equivalent (equal) to the specific friction force $\tau_{w / \sigma}$ in the TFS under study. In addition, a new parameter of the force interaction in the TFS is adopted: the friction index $f_{F}^{\prime}=\sigma_{a} / p_{a}$. Finally, it is established that the direction of the friction force in the TFS $\left(\tau_{w / \sigma}, F_{s / \sigma}\right)$ does not coincide with the direction of motion, i.e. with a friction force $\left(\tau_{w}, F_{s}\right)$ in the FP, similar to the TFS.

According to the generalized law, the specific force and coefficient of friction in the TFS $\left(\tau_{w} / \sigma, f_{s / \sigma}\right)$ can be greater, less than or equal to those $\left(\tau_{w}, f_{s}\right)$ in the FP:

\section{Deformation approach}

$$
\tau_{w / \sigma} \gtreqless \tau_{w}, f_{s / \sigma} \gtreqless f_{s} .
$$

With this approach, the solution of the problem of determining the force and coefficient of friction in the TFS is carried out using the methods of mechanics of a deformable solid, mechanics of contact interaction and the theory of elasticity [17-19].

Theoretically, the friction force in the TFS $F_{\sigma / p}$ can be considered as a function of the usual frictional force during sliding (rolling) $F^{(s)}$, which occurs in the circumferential direction (object - FP), and the non-contact component $F^{(b)}$ of the friction force, which additionally occurs due to the excitation of non-contact (cyclic) stresses (deformations) (Figure 3). In the general case, the friction force in the TFS is represented as the vector sum of the components $F^{(s)}$ and $F^{(b)}$ :

$$
\mathbf{F}_{\sigma / p}=\mathbf{F}^{(s)}+\mathbf{F}^{(b)} \text {. }
$$

Methods for determining $F^{(s)}$ are known [7, 17-19], and methods for determining $F^{(b)}$ have been developed in a new section of mechanics - Tribo-Fatigue [50-52].

Specifying this (vector) sum leads to the following equation:

$$
\begin{gathered}
F_{\sigma / p}=F^{(s)}+F^{(b)}=\int_{S} f^{(s)} p(x, y) d s= \\
=\int_{S} f^{(s)}\left[p_{c}(x, y)+p_{b}(x, y)\right] d s=f^{(s)}\left(F_{N}+P_{b}\right),
\end{gathered}
$$

where $F_{N}$ is the contact load; $P_{b}-$ non-contact load; $p_{s}, p_{b}$ are the forces on the contact area caused by contact (index $s$ ) and non-contact (index $b$ ) loads, respectively; $f^{(s)}$ is the coefficient of friction in the presence of only a contact load, i.e. at FP.

This is the generalized law of friction in the TFS, which is formulated as follows: the generalized friction force $F_{\sigma / p}$ in the TFS is proportional to both the contact load $\left(F_{N}\right)$ and the non-contact force co-directed with it $\left(P_{b}\right)$ due to the non-contact (volumetric) load. Thus, the formulations of the generalized law of friction obtained with the phenomenological and deformation approaches coincide. And again it is predicted that the direction of the friction force in the TFS generally does not coincide with the direction of motion.

After simple transformations, the friction coefficient in the TFS can be written in the following form:

$$
f_{\sigma / p}=f^{(s)}\left[1+k_{\sigma / p}\left(\frac{\sigma_{y y}^{(b)}}{p_{0}}\right)\right],
$$

where $p_{0}$ is the maximum of the $p$ distribution; $k_{\sigma / \mathrm{p}}$ is the friction function due to the interaction of stresses from non-contact and contact loads. Comparison shows that the formulas for the generalized friction coefficient obtained with the phenomenological $\left(f_{s / \sigma}\right)$ and deformation $\left(f_{\sigma / p}\right)$ approaches are formally the same. Naturally, they predict identical dependences of the rolling resistance coefficient in the TFS on the friction index. 


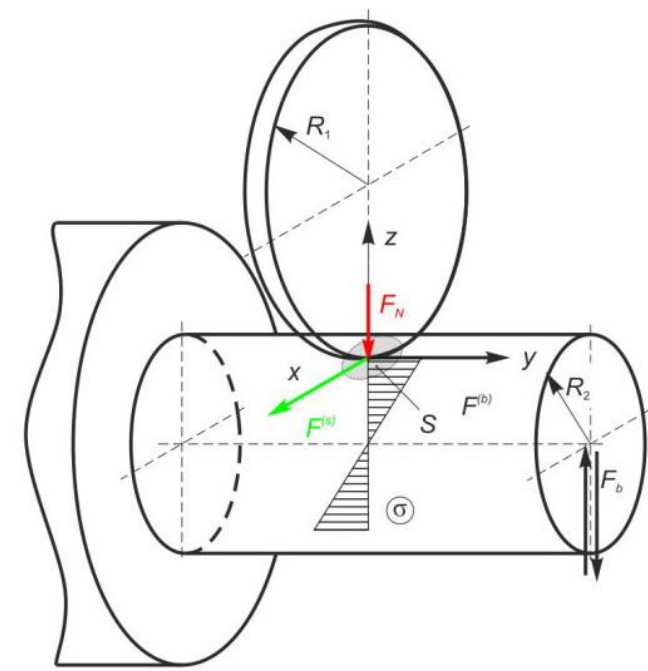

Figure 3 - To the analysis of friction conditions in the TFS of the roller / shaft type

Figure 4, $a$ shows typical surfaces of the values of the friction coefficient at various values of contact and non-contact loads. The linear dependence of $f_{\sigma / p}$ values on $\sigma_{y y}{ }^{(b)} / p_{0}$ is confirmed (see Figure $4, b$ ). It can be seen that the greatest deviation of the friction coefficient in the TFS from the coefficient of friction in the FP will be at the highest absolute value of the ratio $\sigma_{y y}{ }^{(b)} / p_{0}$; it can reach $20 \%$ or more, depending on the test conditions.
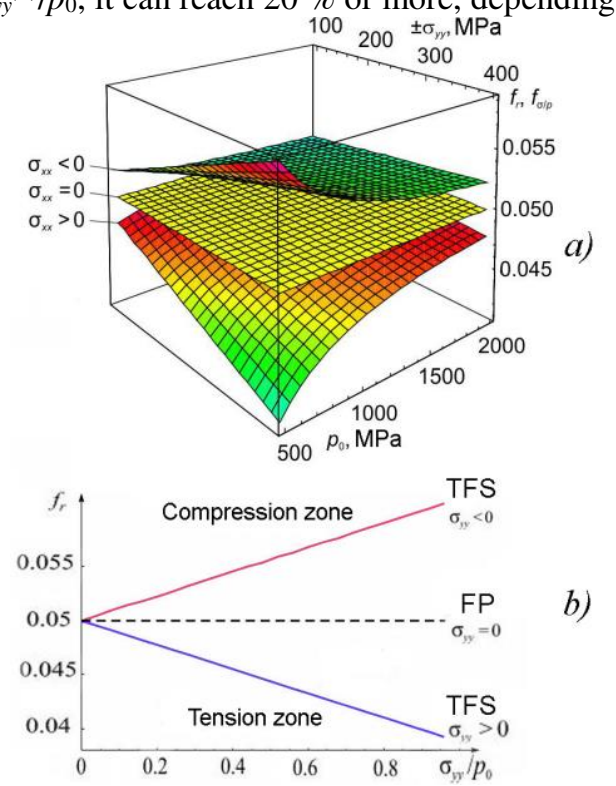

Figure 4 - Spatial dependences $(a)$ of the rolling resistance coefficients in the TFS (at $\sigma_{x x} \gtrless 0$ ) and the corresponding friction pair (at $\sigma_{x x}=0$ ), the partial function of the influence of the friction index $(b)$ on the change in the values of the rolling resistance coefficients at $p_{0}=750 \mathrm{MPa}$

\section{Experimental research}

\subsection{Test procedure}

Two steel grades were accepted for testing, the tensile strength of which differed by $\sim 2.5$ times: carbon steel $0.45 \% \mathrm{C}\left(\sigma_{u}=610 \mathrm{MPa}\right)$ and alloy steel $18 \mathrm{CrMnT}\left(\sigma_{u}=1700 \mathrm{MPa}\right)$. The geometrical dimensions of the elements (shaft, roller) of the TFS and the schemes of its loading are shown in Figure 5.

The tests were carried out with the organization of rolling friction either in the tension zone $(\sigma>0)$ or in the compression zone $(\sigma<0)$ of the bent shaft (bending load $Q$ is directed upward or downward, respectively, see Figure $5)$. The sample (shaft) and counter-sample (roller) of the tested FP had the same dimensions as the elements of the TFS. To ensure the stability of contact and deformation during testing, the shaft has a groove with a radius of $R=10$ $\mathrm{mm}$, and the profile radius of the roller $R=5 \mathrm{~mm}$ is twice less. And in order to prevent stress concentration in the contact area, the radius of the groove on the sample is equal to its diameter in the working section $(R 10=D 10)(\mathrm{see}$ Figure 5). 

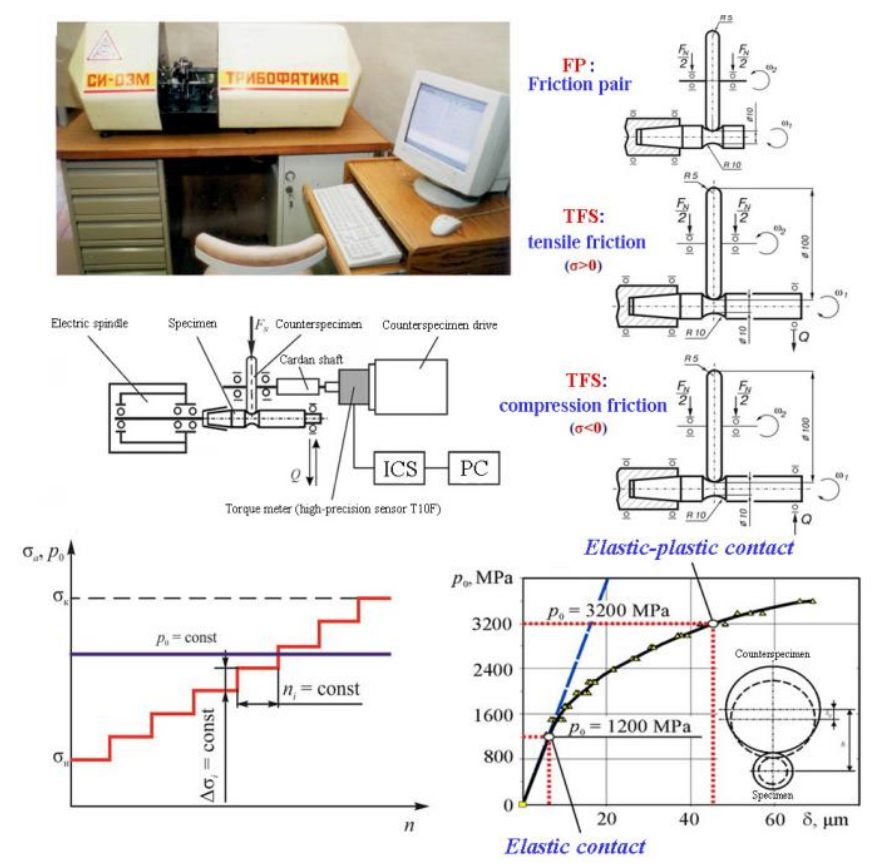

Figure 5 - Photo of the SI-03M universal testing machine and test scheme

Three combinations of materials of rubbing elements (specimens and counter-specimens) have been tested: $0.45 \% \mathrm{C} / 0.45 \% \mathrm{C} ; 18 \mathrm{CrMnT} / 18 \mathrm{CrMnT} ; 0.45 \% \mathrm{C} / 18 \mathrm{CrMnT}$. The highest contact pressure $\left(p_{0}\right)$ is determined according to Hertz. Its values are such as to realize elastic or elastoplastic contact. The nature of the contact is established according to the diagram $p_{0}-\delta$ ( $\delta$ is the convergence of the axes of the TFS or FP elements) (see Figure 5). The tests varied: cyclic stresses from 160 to $640 \mathrm{MPa}$ (4 times); contact pressure from 1200 to $3200 \mathrm{MPa}$ (more than 2.5 times); friction index in TFS $\left(f_{F}=\sigma_{a} / p_{0}\right)$ from 0.1 to 0.3 ( 3 times).

All tests were carried out on one SI-03M wear-fatigue testing machine (see Figure 5) at a frequency of 3000 $\mathrm{min}^{-1}$ and normal ambient temperature and humidity in accordance with GOST 15150-69 [58]. The parameters of the testing machine met all the requirements of the GOST 30755-2001 standard [59]. The technique of accelerated tests at multistage loading according to STB 1233-2000 [60] was applied (see Figure 5). Each test was repeated three times. All tests were carried out in accordance with the requirements of GOST 30754-2001 [61].

\subsection{Test results}

The test results are shown in Figures 6-8. They were processed in accordance with the generalized law of friction for TFS, i.e. plotted the dependence of the rolling resistance coefficients $f_{\sigma / p}$ on the value of the friction index $\sigma_{a} / p_{0}$. The results of data processing are presented in Figures 6-8. The study of these experimental data leads to the following main conclusions.

It has been experimentally established (Figures 6-8) that the rolling resistance coefficient in the TFS $\left(f_{\sigma / p}\right)$, as a rule, is significantly greater or less than that $\left(f_{r}\right)$ in the analogous FP. The relative difference $\left(\Delta_{\max }\right)$ between them under the conditions of the experiment reaches $\Delta_{\max }=60 \ldots 70 \%$ and more (Figure 9). Consequently, the practical use of the classical law for the analysis of friction in TFS is inappropriate, since it leads to a significant error in the calculations. The application of the generalized law of friction removes this problem.

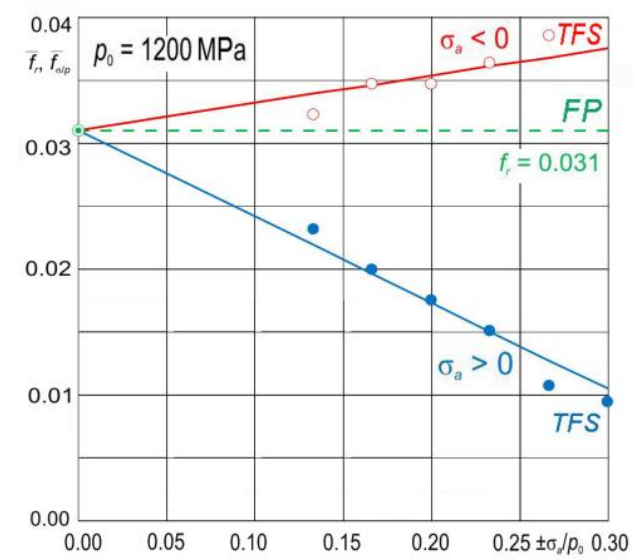

Figure 6 - Analysis of test results for TFS $0.45 \% \mathrm{C} / 0.45 \% \mathrm{C}$ 


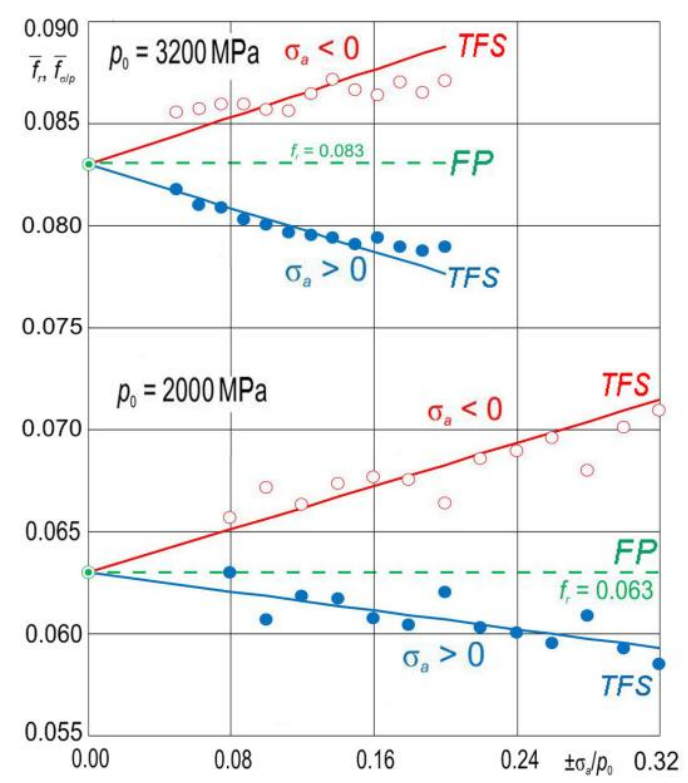

Figure 7 - Analysis of the test results for TFS 18CrMnT / 18CrMnT

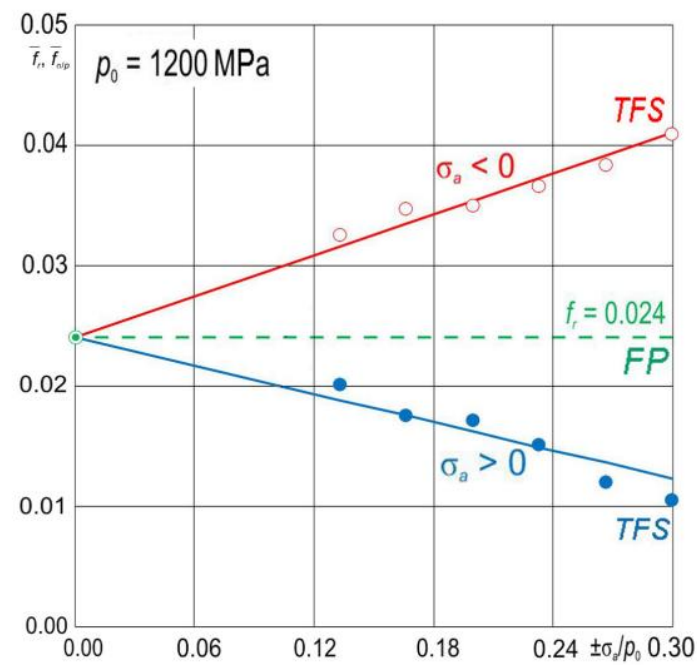

Figure 8 - Analysis of test results for TFS $0.45 \% \mathrm{C} / 18 \mathrm{CrMnT}$
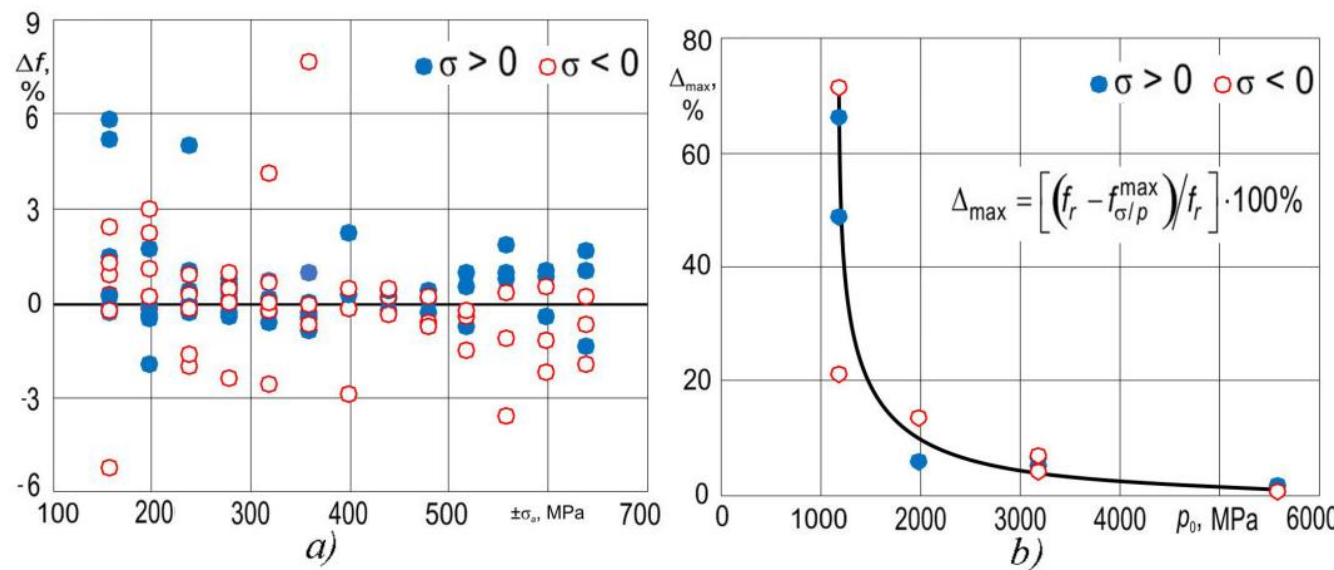

Figure 9 - Analysis of the error of approximation of experimental data by the generalized law of friction $(a)$ and the largest $\Delta_{\max }$ (in experiments) difference between the rolling resistance coefficients in TFS and FP depending on the values of contact pressure $(b)$

The generalized law of friction approximates the results of all experiments (about 100 values of the rolling 
resistance coefficients) with an error that falls within the interval $\Delta_{f}= \pm 6 \%$; in $90 \%$ of cases it is $\pm 3 \%$ (see Figure 9). The error of the generalized law turns out to be approximately the same when friction is realized both in the compression zone and in the tension zone of the bent shaft. This allows us to recommend it for practical calculations.

The generalized law of friction is equally effective for describing friction in elastic and elastoplastic contacts (see Figures 6-8). The largest difference between the values of the rolling resistance coefficient in FP and TFS decreases with increasing contact pressure. This means that the error of the classical law of friction is especially large for elastic contact (more than $20 \%$ ), while under conditions of elastoplastic contact it is much less (less than $10 \%)$.

Taking into account the influence of the friction speed, the generalized law of friction has the form [1]

$$
F_{s / \sigma}=\left\{\begin{array}{l}
\left(f_{s} F_{N} \pm \mu_{\sigma} M_{i j k}\right) \frac{v_{s}}{\left|v_{s}\right|} \text { for } v_{s} \neq 0, \\
\left|-F_{s / \sigma}^{(0)},+F_{s / \sigma}^{(0)}\right| \text { for } v_{s}=0, F_{s / \sigma}^{(0)} \geq F_{s}
\end{array}\right.
$$

Here $f_{s}$ is the coefficient of friction; $N$ - pressing force (normal reaction); $v$ is the relative sliding speed. If $v \neq 0$, then the friction force is called the sliding friction force, if $v=0$, then the friction force belongs to the interval indicated in square brackets and is called the static friction force. Its value in this interval is determined from the equilibrium condition of the body at rest.

The generalized law of friction is named after Sosnovsky - Sherbakov - Komissarov [2].

\section{References}

1. L. A. Sosnovskiy. The law of friction: from Tribology to Tribo-Fatigue. Message 1. The classical law of dry friction and the need for its correction // Mechanics of machines, mechanisms and materials. - 2019. - No. 1 (46). - P. 64-76; Message 2. Theoretical research // Mechanics of machines, mechanisms and materials. - 2019. - No. 2 (47). - P. 66-77; Message 3. Experimental research // Mechanics of machines, mechanisms and materials. - 2019. - No. 4 (49). - P. 95-106. (in Russian).

2. L. A. Sosnovskiy, A. V. Bogdanovich, O. M. Yelovoy, S. A. Tyurin, V. V. Komissarov, S. S. Sherbakov. Methods and Main Results of Tribo-Fatigue Tests // International Journal of Fatigue. - 2014. - V. 66. - P. 207219.

3. Encyclopedia of Tribology / ed. by Q. Jane Wang, Yip-Wah Chung. Springer, 2013. - In 6 volumes. -4139 p.

4. V. F. Zhuravlev. 500 years of the history of the dry friction law // Bulletin of MSTU name N. E. Bauman. Series "Natural Sciences". - 2014. - No. 2. - P. 21-31. (in Russian).

5. Leonardo da Vinci. Selected works of science. - M.: Publishing house of the Academy of Sciences of the USSR, 1955. - 1028 p. (in Russian).

6. E. Popova, V. Popov. On the origin of Amonton's friction law // Friction 3(2): 183-190 (2015).

7. Modern tribology handbook / edited by Bharat Bhushan. - CRC Press, 2001. - 1690 p.

8. Peter J. Blau. Friction science and technology: from concepts to applications. - London-New York: CRC Press, 2009. $-420 \mathrm{p}$.

9. I. V. Kragelsky, V. S. Shchedrov. Development of the science of friction. - M.: Publishing house of the Academy of Sciences of the USSR, 1958. - 234 p. (in Russian).

10. D. Dowson. History of Tribology. - London-NY : Longman, 1979. - 677 p.

11. L. Euler. Sur la diminution de la resistence du frottement. Histoire de L'Academie Royale des Sciences et Belles Lettres a Berlin, 1748. - P. 133-148.

12. C. A. Coulomb. Theorie des machines simples. Mem. Math. et Phys. l'Acad. Sci., 1785. - V. 10. - P. $161-331$.

13. M. Amontons. De la reistance causee dans les machines. Mem. l'Acad. Roy., 1699. - P. 206-222.

14. B. N. J. Persson [et al.]. On the origin of Amonton's friction law // J. Phys.: Condens. Matter 20 (2008) 395006 $(11 \mathrm{p})$.

15. A. Morin. Mem. presentees par divers savants a l'Academie des sciences. 1833, - V. 4. - P. 1-128, - P. 591696; 1835, - P. 641-783.

16. N. E. Zhukovsky. Friction of railway wheel rims against rails. - Collection. - V. 7. -M.-L.: Gostekhizdat, 1950. - P. 426-478. (in Russian).

17. K. L. Johnson. Contact mechanics. Cambridge University Press, 1985.

18. P. J. Vermeulen, K. L. Johnson. Contact of non spherical bodies transmitting tangential forces // Journal of Applied Mechanics. - 1964. - Vol. 31. - No. 2. - P. 338-340.

19. I. G. Goryacheva. Mechanics of frictional interaction. - M.: Nauka, 2001. - 478 p. (in Russian).

20. G. Tomlinson. A molecular theory of friction // Phil. Mag. - 1929. - V. 7. - No. 46. - P. 907-939.

21. F. R. Bowden, D. Tabor. Friction and lubrication. - M.: Mashgiz, 1960. - 101 p.; they are: Friction and lubrication of solids. - M.: Mashinostroenie, 1968. - 543 p. (in Russian). 
22. C. Rubenstein. The coefficient of friction of metals // Wear. - 1958. - V. 2. - No. 2. - P. 85-96.

23. Peter J. Blau. The significance and use of the friction coefficient // Tribology International. - V. 34. - Issue 9. September 2001. - P. 585-591.

24. F. F. Ling, E. Saibel. On kinetic friction between unlubricated metallic surfaces // Wear. - 1957. - V. 1. - No. 3. - P. 167-172.

25. P. R. Dahl. A solid friction model // The Aerospace Corporation. Technical report, 1968. - $260 \mathrm{p}$.

26. P. R. Dahl. Measurement of solid friction parameters of ball bearings // The Aerospace Corporation. Technical report, 1977. $-236 \mathrm{p}$.

27. A. Yu. Ishlinsky. Mechanics: ideas, tasks, applications. - M.: Nauka, 1985. - 624 p. (in Russian).

28. N. M. Alexeyev. On the motion of material in the border layer in solid state friction // Wear. - 1990. - V. 139. P. 33-48.

29. Jr. D. A. Haessig, B. Friedland. On the modeling and simulation of friction // Journal of Dynamic Systems, Measurement and Control, Transactions of the ASME. - 1991. - No. 113 (3). - P. 354-362.

30. M. Gafvert. Comparisons of two dynamic friction models. 1997. - P. 386-391.

31. B. Bhushan. Principles and applications of tribology. - N.Y.: Willey, 1999. - 390 p.

32. J. Swevers [et al.]. An integrated friction model structure with improved presliding behavior for accurate friction compensation // IEEE Transactions on Automatic Control. - 2000. - No. 45 (4). - P. 675-686.

33. V. Lampaert, J. Swevers, and F. Al-Bender. Modification of the Leuven integrated friction model structure // IEEE Transactions on Automatic Control. - 2002. - No. 47 (4). -P. 683-687.

34. F. Al-Bender, V. Lampaert, J. Swevers. A novel generic model at asperity level for dry friction force dynamics // Tribology Letters. - 2004. - No. 16 (1-2). - P. 81-94.

35. G. Jianping [et al.]. Frictional forces and Amonton's law: from the molecular to the macroscopic scale // J. Phys. Chem. B 2004, 108, 3410-3425.

36. F. Al-Bender. On the definition and laws of friction // Proc. of World Tribology Congress II : Washington, D.C. USA, September 12-16, 2005. - Washington, 2005.

37. A. A. Merzlyakov. On external friction and the law of friction // Omsk scientific bulletin. - 2006. - No. 4 (38). P. 77-81. (in Russian).

38. D. A. Rigney, J. P. Hirth. Plastic deformation and sliding friction of metals // Wear. - 1979. - V. 53. - P. $345-$ 370.

39. N. P. Suh, P. Sridharan. Relationship between the coefficient of friction and the wear rate of metals // Wear. 1975. - V. 34. - No. 3. - P. 291-299.

40. V. I. Pozhbelko. New analytical laws and universal constants of limiting friction and wear of friction of solids // Friction, wear, lubrication. - 2010. - V. 13. - No. 43. - P. 1-9. (in Russian).

41. B. Armstrong-H'elouvry, P. Dupont, C. Canudas de Wit. A survey of models, analysis tools and compensation methods for the control of machines with friction // Automatica. - 1994. - No. 30. - P. 1083-1138.

42. P. Dupont [et al.]. Single state elastoplastic friction models // IEEE Transactions on Automatic Control. - 2002. - No. 47 (5). - P. 787-792.

43. J. R. Barber. Multiscale Surfaces and Amontons' Law of Friction // Tribology Letters, 2013. 49(3): p. $539-543$.

44. Ando, Y., Tamura, Y., Takahashi, H. et al. Experimental Studies on Revealing a Dominant Factor in Friction Coefficient Between Different Metals Under Low Load Conditions // Tribology Letters 47, 43-49 (2012).

45. Burris, D.L., Sawyer, W.G. Addressing Practical Challenges of Low Friction Coefficient Measurements // Tribology Letters 35, 17-23 (2009).

46. Patil, D.B., Eriten, M. Effects of Interfacial Strength and Roughness on the Static Friction Coefficient // Tribology Letters 56, 355-374 (2014).

47. Proceedings of the III International Symposium on Tribo-Fatigue (ISTF 2000), Beijing, China, Oct. 22-26, 2000 / ed. by Gao Wanzhen and Jian Li. - Beijing : Hunan University Press, 2000. - 653 p.

48. L. A. Sosnovskiy, V. T. Troshchenko, N. A. Makhutov, Gao Wanzhen, A. V. Bogdanovich, S. S. Sherbakov. Wear-fatigue damages and their prediction (Tribo-Fatigue); ed. by L. A. Sosnovskiy. - Gomel - Kiev - Moscow - Wuhan, 2001. - 170 p. (in Russian).

49. L. A. Sosnovskiy. Fundamentals of Tribo-Fatigue : in 2 pt. - Gomel : BelSUT, 2003. - V. 1. - 246 p.; V. 2. 234 p. (in Russian); L. A. Sosnovskiy. Tribo-Fatigue. Wear-Fatigue Damage and Its Prediction // Series : Foundations of Engineering Mechanics, Springer, 2005. - 424 p.; 摩擦疲劳学 磨损 - 疲劳损伤及其预测. L. A.

索斯洛-夫斯基著, 高万振译 - 中国矿业大学出版社, 2013. - 324 p.

50. S. S. Sherbakov, L. A. Sosnovskiy. Mechanics of tribo-fatigue systems. - Minsk: BSU, 2010. - 407 p. (in Russian).

51. L. A. Sosnovskiy. Mechanics of wear-fatigue damage. - Gomel: BelSUT, 2007. - 434 p. (in Russian).

52. L. A. Sosnovskiy, M. A. Zhuravkov, S. S. Sherbakov. Fundamental and applied tasks of Tribo-Fatigue: lectures. - Minsk: BSU, 2010. - 488 p. (in Russian). 
53. S. S. Sherbakov. Change in force and coefficient of friction under the action of non-contact load (theoretical analysis) // Bulletin of BelSUT: Science and transport. - 2016. - No. 1 (32). - P. 110-115. (in Russian).

54. L. A. Sosnovskiy, V. V. Komissarov, S. S. Sherbakov. Technique for experimental study of friction in a active system // Friction and wear. - 2012. - V. 33. - No. 2. - P. 174-184. (in Russian).

55. S. A. Tyurin, S. S. Sherbakov, L. A. Sosnovskiy. Comparative study of friction coefficients during and mechano-rolling fatigue // Industrial laboratory. Diagnostics of materials. - 2005. - V. 71. - No. 2. - P. 48-51. (in Russian).

56. L. A. Sosnovskiy, V. V. Komissarov, S. S. Sherbakov. Comparative experimental study of friction parameters in a friction pair and a active system // Friction and wear. - 2012. - V. 33. - No. 3. - P. 258-264. (in Russian).

57. Friction coefficient tables (https://dpva.ru/Guide/GuidePhysics/Frication/).

58. Machines, devices and other technical products. Versions for different climatic regions. Categories, operating conditions, storage and transportation in terms of the impact of climatic factors of the external environment (Interstate standard): GOST 15150-69. - Introduced 01.01.1971. - M: Standartinform, 2002. - 57 p. (in Russian).

59. Tribo-Fatigue. Wear-fatigue tests machines. General technical requirements (Interstate standard): GOST 30755-2001. - Introduced 01.07.2002. - Minsk: Interstate council for standardization, metrology and certification : Belarusian state institute of standardization and certification, 2002. - 8 p. (in Russian).

60. Tribo-Fatigue. Wear-fatigue tests methods. Accelerated mechano-rolling fatigue tests (Standard of Belarus): STB 1233-2000. - Introduced 01.01.2001. - Minsk: Gosstandard, 2000. - 8 p. (in Russian).

61. Tribo-Fatigue. Wear-fatigue tests methods. Mechano-rolling fatigue tests (Interstate standard): GOST 307542001. - Introduced 01.07.2002. - Minsk: Interstate council for standardization, metrology and certification: Belarusian state institute of standardization and certification, 2002. - 32 p. (in Russian). 